\title{
Uma visão da Europa em expressões plásticas ameríndias
}

\section{EDUARDO PEÑUELA CAÑIZAL}

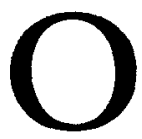

$s$ códices criados pelas principais culturas mesoameríndias diferem tanto na apresentaçáo dos eventos quanto no estilo. Indubitavelmente, os códices maias são distintos dos mixtecos e mexicanos. No passado, houve quem, baseado nas diferenças existentes entre expressóes pictóricas dos antigos habitantes da América Central, comparasse, por exemplo, os códices maias com a Escola Flamenga, os mixtecos com os trabalhos da Escola de Siena e os astecas com os florentinos. Contudo, essas extraordinárias expressóes pictóricas de trabalho indígena constituem um espaço significativo estruturado pela intervençáo de três sistemas de escrita:

- o pictográfico;

- o ideográfico;

- o fonético.

Consequientemente, como resultado lógico, as mensagens nesses códices geralmente assumem formas de condensação superdemarcadas pela função que cada um dos sistemas mencionados desempenha. É isto o ignorado quando săo feitas comparaçóes entre as imagens dos códices e as mais características configuraçóes da pintura européia, de vez que sé deve levar em consideração que, mesmo " cuando existen parios estudios sobre la escritura prebispánica, queda auin un amplio campo de investigar, acudiendo a los manuscritos indigenas, tanto precolombianos, como de la primera etapa de la Colonia, o sea del siglo XVI, en el que aún se conserraba bastante pura la técnica precolombiana" (León-Portilla, 1989:195).

Algumas vezes, são estabelecidas semelhanças baseadas em certas analogias superficiais, relegando assim ao plano do desconhecido meios de expressáo fundamentais para o paciente exercício de alcançar o território de significados mais obscuros de alguns objetos culturais. Entre seus muitos valores, esses objetos têm também o mérito de nos fazer ver com maior precisáo traços inesperados de imagens da Europa, quando eles ganham uma nova expressão em outras culturas. Lembrando-nos disso, o objetivo de nosso trabalho é explorar determinadas formas que surgem quando o intérprete dos códices mesoamericanos pára a fim de pensar sobre os tipos de relaçóes mantidas pelos diferentes sistemas no 
espaço plástico do texto. Dessa perspectiva, podemos avaliar o significado poético de metáforas nas quais os ameríndios expressam visóes peculiares do povo e objetos europeus. É sobre uma dessas metáforas que falaremos neste Congresso; sobre a metáfora que reconcilia o pragmatismo tecnológico dos objetos - representados aqui pelas primeiras naus que chegaram ao Novo Mundo - com o gesto primordial que esses mesmos objetos escondem.

O fato de escolher naus, entre os objetos tecnológicos, é sem dúvida uma opção de natureza metonímica, que de forma alguma anula o peso metafórico com os quais esses objetos estão investidos, em termos de representaçóes concretas da técnica e história da Europa renascentista. De um lado, a nau adquire grande relevância quando se a considera como fruto da ciência bastante disseminada durante a Renascença. Conforme o que agora sabemos sobre o assunto, é uma ciência crítica baseada na observação e experimentos para o que contribuíram, de maneira decisiva, vários navegantes de naçóes européias. De outro lado, se tomarmos a caravela como paradigma da nau, é preciso concordar, por exemplo, com as idéias de Vegio Melegari e admitir que as caravelas de Colombo " sono state per secoli un mistero e in gran parte lo sono ancora. La Santa Maria ì la piu celebre fra tutte le navi della storia e della leggenda. Soltanto l'Arca de Noe Le insidia tale primato. Ma come realmente fosse, dentro e fuori, nessuno ì in grado de dirlo. E stata iricostruitau piu polte, al vero e in scala ridotta, ma la sua sagoma reale si è perduta per sempre com lei, in quella notte di Natale del 1492, quando si arend dapanti al promontorio che Colombo, in omaggio all Evento imminente, apepa battezzato Punta Santa "' (1991:78). Essa ambigüidade certamente nos interessa, à medida que dá origem à impossibilidade de se ter uma imagem exata das naus do descobrimento e, assim, tal como os nativos do Novo Mundo, há séculos atrás, o próprio homem contemporâneo parece destinado a se enfrentar com suposiçóes que, por vezes, o assombram e desnorteiam.

Talvez os mistérios aos quais Melegari se refere e a persistência da incerteza prolongam, de certa forma, essa intertessitura de enigmas dos quais o Padre Antonio Vieira fala na sua Historia do Futuro quando relata, baseado nas profecias de Isaías, as extraordinárias coincidências entre as naus romanas $\mathrm{e}$ as dos índios maranhenses. Ambas são naus em forma de sino, com asas (náo se pode também esquecer que as caravelas são transformações de pequenos barcos mouriscos chamados carabus, termo que também pode ser empregado para designar insetos da família Carabidae, e que o processo todo da homonímia pode engendrar terrível confusão). Mas, para explicar a metáfora oculta do nome rostratas, usado pelos romanos para designar suas galeras de guerra, o Padre 
Antônio Vieira transcende os limites da retórica barroca e penetra em território inusitado - referindo-se aos textos proféticos - afirmando: "Digo pois que fala o texto de verdadeiras asas de aves. Como aqueles gentios não tecem, nem têm panos, é grande entre eles o uso de penas pela formosura das cores com que a natureza vestiu os pássaros, e particularmente o chamado guarás, de que há infinita quantidade, grande e todos vermelhos, sem mistura de outra cor; destas penas se enfeitam quando se querem pôr bizarros, e principalmente quando váo à guerra, ornando com elas todo o gênero de armas, porque não só levam empenadas as setas, senão também arcos e rodelas, e as partazanas de pau $\mathrm{e}$ pedra que chamam fangapenas: e quando a guerra era naval empavezavam-se as canoas com as asas vermelhas dos guarás, e por isso o Profeta diz que todas estas cousas via e notava como táo novas: chamou as lanças sinos e sinos asas: Navium alis, cymbalo alarum (1953:242-243). Assim, parece que, a despeito da tecnologia, os objetos criados pelo homem preservam irradiaçóes metafóricas que revelam a existência de gestos primordiais soterrados sob as proezas clamorosas que frequientemente alimentam a História.

Contudo, a força mais eficaz para exumar da poeira da História significados dessa natureza se origina na intensidade do choque provocado pelo confronto de culturas muito díspares. Segundo o testemunho de Alvarado Tezozómoc em sua Crónica Mexicana, isto é confirmado pela estória do macehual que foi diretamente ao palácio de Motecuhzuma assim que chegou à cidade do México e the disse: "señor $y$ rey nuestro, perdóname mi atrevimiento. Yo soy natural de Mictlancuaubtla; llegué a las orillas de la mar grande, y vide andar en medio de la mar una sierra o cerro grande, que andaba de una parte a otra y no llegaba a las orillas, $y$ esto jamás hemos visto, $y$ como guardadores que somos de las orillas de la mar, estamos al cuidado " (León-Portilla, 1989:15). Não se pode duvidar que o macehual jamais tivesse visto antes aquelas naus que se aventuravam de um lugar para outro. $O$ que precisamos examinar naturalmente são as metáforas que este homem do povo usa para designar o objeto com o qual se depara pela primeira vez.

Se considerarmos as características estruturais dos textos indígenas e europeus do século XVI, examinando os diversos encontros nos quais culturas tão diferentes participaram dos territórios hoje conhecidos como México e Guatemala, podemos tratar com certos componentes, cujas particularidades sem dúvida nos ajudarão a entender o universo semântico que permite o estabelecimento de identidades e diferenças. Conseqüentemente, deveríamos mencionar que $o$ universo semântico autenticará, no primeiro contato, o sentido superficial assu- 
mido pela metáfora e ajudará, em contatos posteriores, $\mathrm{o}$ intérprete dessas metáforas a descobrir significados mais profundos.

No caso dos textos que compóem os códices, as mensagens estão geralmente ordenadas, como já foi dito, de acordo com os princípios ditados pelos três sistemas de representação básica - pictórico, ideográfico e fonético - sobre os espaços dos códices que se desdobram como biombos " se repartissaient des objets, des personnages et des formes géometriques dont la représentation stylisée se pliait à de canons précis et rigides qui permettaient d'identifier sans équipoques les concepts, les etres et les choses: souperains, seigneurs, parures, armes, mobilier, eléments d'architecture" (Gruzinski, 1991:14).

Assim, na primeira página com detalhes do Códice Mendoza (figura 1), vemos uma águia pousando num cacto nopal e um escudo e flechas simbolizando guerra no centro; à direita, uma espécie de altar ou paliçada, com um crânio humano; dez indivíduos sentados em esteiras ocupam os quatro campos triangulares limitados por canais ou valas de irrigaçáo. Os pequenos tufos de plantas, na opiniáo de Soustelle (1984:2), estáo espalhados por tudo para lembrar a natureza da terra onde foi construído o templo de Huitzilopochtli, representado pela estrutura localizada no meio dos índios, no triângulo superior.

Se nos aproximarmos mais do centro, poderemos ver, tal como aparecem nesta reprodução (figura 2), que as plantas às quais se refere Soustelle significam tufos de junco selvagem. Em outras palavras, plantas que o homem ainda não havia cultivado. Deixando de lado o detalhe, torna-se evidente que o criador da imagem queria representar o momento exato em que a águia pousou nas peças suculentas, cobertas de espinhos, de um cacto nopal. Todos esses significados são derivados do sistema pictográfico e, se não fôssemos além, nossa leitura seria muito pobre. Precisamos abordar os outros dois sistemas. Um deles aparece na figura sobre a qual repousa o cacto. É a representaçáo de uma pedra tetl em Nahuatl -, um símbolo que associado com o cacto - nochtli, na língua dos Nahuas - e o sufixo tlan, forma o ideograma representando o nome Tenochtitlan, no sistema fonético, a cidade fundada quando a águia, símbolo da Huitzilopochtli, pousou no ramo do cacto para indicar o local.

Se, além disso, quisermos saber o nome das pessoas que guardavam o templo (nesta reproduçáo, figura 3 ), construído em homenagem ao referido deus, precisamos seguir a interpretação de Escalona: - Para nombrar al personaje de la derecha, primero leemos el contenido 'cuahtli-ibuitl: plumas de águila... después, lo que las contiene, que es 'pantli', bandera... y al final, la particula reperencial 'tzin', el venerado. Es el 

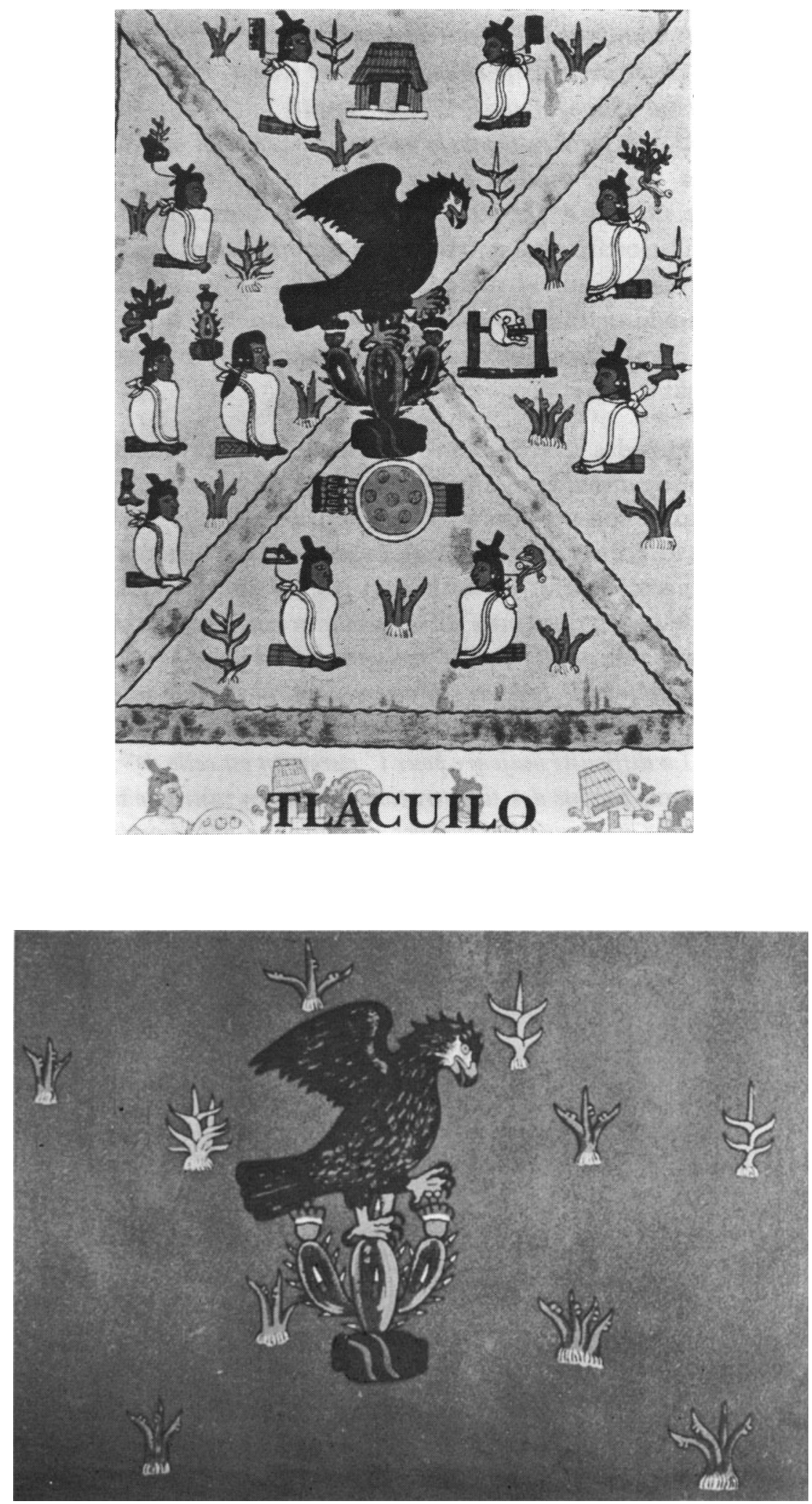
Venerado Cuaubpan, Bandera de Plumas de /'aguilaw / En el otro personaje seria, seguin las leyes de lectura: 'ocelo-ebualtl', piel de ocelote. Para leer, solo usamos las tres primeras silabas... 'ocelo'... De 'pantli', nos quedamos con uma sola silaba: 'pan'... al final emitimos la particula de respeto 'tzin'. Ast, formamos la palabra 'Ocelopantzin', que traduciremos por 'El Respetado Bandera de Piel de Ocelote' "(1989:69). Os três sistemas de representaçáo também funcionam aqui e precisamos ter $\mathrm{em}$ mente que o pictográfico não expressa a individualidade inequívoca da personalidade humana, embora ajude o fonético a adquirir singularidade instigante: nesses quadros, os nomes próprios não são arbitrários, como os cronistas espanhóis chamaram os códices.

Vistas em termos das relaçóes entre si dentro do próprio texto, as mensagens são heterogêneas, com a particularidade de que os sistemas intervindo na estrutura concreta do texto privilegiam relaçóes intratextuais. Isto é, eles favorecem conexões de elementos de um sistema com elementos de outro sem superar os limites da página em que cada um deles se manifesta. Assim, o que torna difícil a compreensáo desta escrita é " $l$ 'utilisation absolue des 'images'. Il faut connautre, $d$ ' une part, le système plastique pour traduire le code, et, $d$ 'autre part, la langue nabuatl, pour suipre $l$ 'un et $l$ 'autre conjointement et arriver jusqu' 'à la lecture complète des 'tableaux'. La difficulté majeure pour l' européen est celle de 'voir', les dessins autrement que comme des illustrations', mais en tant que transcription de note, comme un texte précis dans une langue determinée. Les 'images' astèques traditionnelles sont le 'texte' meme. Il n' y a pas dans la

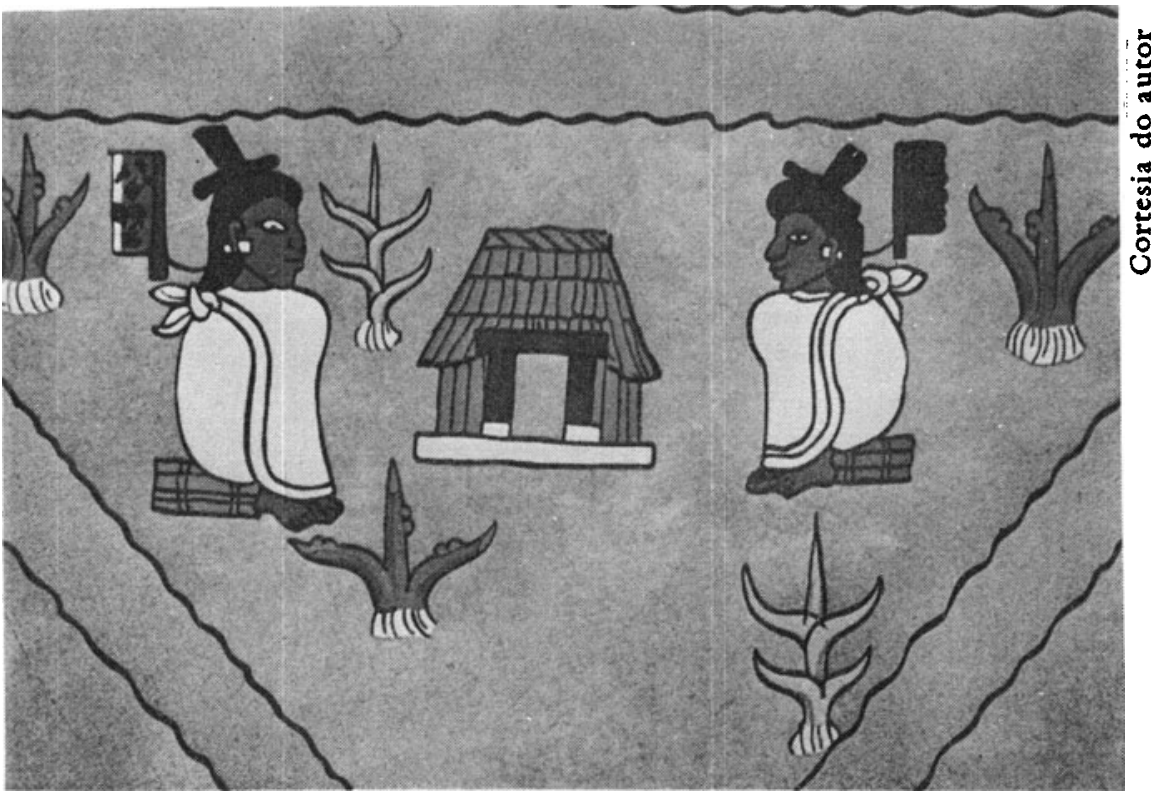

Fig. 3: Códice Mendoza 


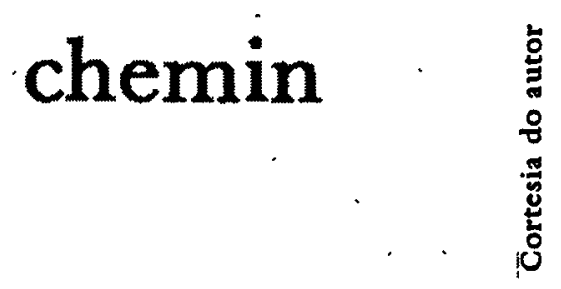

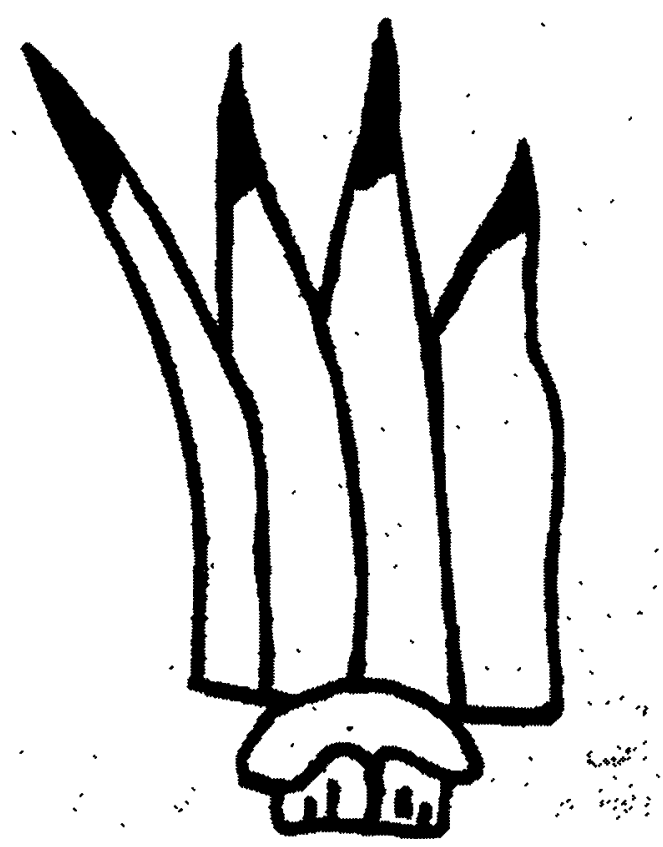

Fig. 4: Hiroglifo Asteca

conception indigine de stpuration du texte et de l'illustration, comme en Europe" (Galarza, 1978:17).

Além de ser uma chave para a leitura, precisamos considerar a intertextualidade como um processo do qual dependem os modos expressivos que favorecem a manifestação dos significados comprometidos com mecanismos primordiais de percepçáo, e privilegiando assim o poder dos mais autênticos instintos humanos. Nesse sentido, a intratextualidade também funciona como um tipo de marca que preserva certos indícios de uma maneira de ser metafórica de situar-se no mundo, e conviver com suas circunstâncias. É precisamente isto que se estabelece quando descobrimos que a relaçáo de identidade responsável - nesta configuração hieroglífica asteca (figura 4) - pela associaçăo de penas com dentes a fim de formar o nome Cuetzaldin: cuezalli (penas vermelhas de quetzal) e tlantli (dente). Talvez as penas e dentes não apenas se assemelhem por serem incrustados, mas também porque tanto umas quanto outros são, na verdade, órgáos de sustento vital que, encarados da perspectiva humana, também tornam manifesta a necessidade de 
sobrevivência cultural, uma vez que, como nos lembra Zunzunegui, o processo para uma fonetização năo é algo irreversível nem " se trata de una meta alcanzada dejando atrás la 'iconicidad' e insertándose de lleno en la arbitrariedad signica. Porque estas representaciones mantenian un doble nivel de lectura 'seguin la audiencia' a la que se dirigian. Los textos inscritos en los monumentos, destinados a la contemplación popular, cargaban la mano en los aspectos icónicos, mientras que los destinados al consumo real o de la casta sacerdotal utilizaban más las correspondencias fonéticas. Otro tanto puede decirse de los jeroglificos egipcios y su mantenimiento a lo largo de 3.000 años, quizás como poluntaria forma de control del saber y como garantía de aislamiento con respecto al exterior" (1992:104).

Os europeus trouxeram para a Nova Espanha livros ilustrados, tapeçaria, gravuras e pinturas, que desafiavam a maneira de ver da população nativa. Frutos de codificação de processos básicos - icônico e iconográfico - , as imagens desses textos ofereciam uma diversidade de pontos de vista. Os signos icônicos revelavam modos diferentes de perceber o mundo, embora qualquer habitante de qualquer país europeu daquele período pudesse decifrá-los, sem nenhuma dificuldade. De tudo isto podemos entender o sucesso que algumas ilustraçóes daquele período alcançaram nas mais variadas naçóes do Velho Continente. Os signos iconográficos não foram entendidos táo facilmente, uma vez que muitos dos habitantes não sabiam, digamos, que uma figura feminina com corpo de leão e asas pudesse significar Quimera. Qualquer que seja o caso, do ponto de vista dos povos indígenas, esses animais monstruosos disseminados pela iconografia européia ocultavam uma fascinação irresistível. Sua curiosidade incidia sobre formas cujos paradigmas poderiam ter sido aqueles seres fantásticos inventados por Boch a fim de povoar quadros como El Jardin de las Delícias ou Las tentaciones de San Antonio.

Reminiscências dessa atração acham-se em formas monstruosas desse tipo, encontradas em ilustraçóes sul-americanas do século XVIII. Porém, no caso específico da Nova Espanha, essa atração parece ter tido suas raízes no próprio estilo de arte asteca. Se nos detivermos diante da estátua de Coatlicue (saia de serpentes), necessariamente sentiremos um arrepio que vem das imagens que a compóem (figura 5), de vez que, como nos relata D'Ors Führer, "No habia posibilidad de un equilibrio en el arte, que en Egipto y en Grecia fue el origen de la civilización occidental. Todo lo que era muerte les estaba pedado. La estética es por lo tanto, manifestada a traves de representaciones de muerte, destrucción, poder terrorifico, eterno fluir. La diosa de la muerte, Coatlicue, cubierta de garras y serpientes, $y$ alzando su rostro de esqueleto y el horror de sus manos podridas, obedece en su bloque y en su estructura a una simetria. Una mitad es exactamente igual a la otra (limitación de dos puntos, materialidad, principio de todo fluir y 


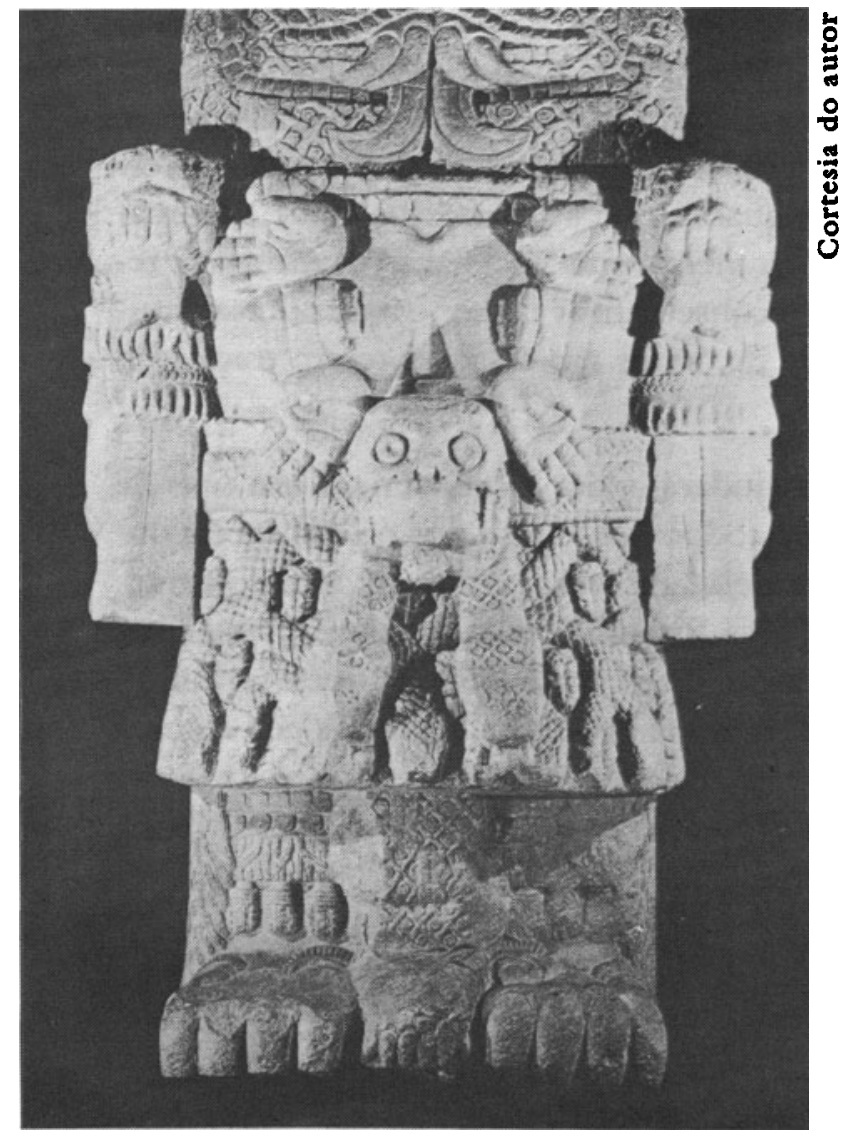

Fig. 5: Coatlicue

acaecer). Se nos presenta esta escultura como un inmenso bloque de piedra pesado, en cuyos elementos acusados como un 'colage' en reliepe, se nos da la explicación del aterno fluir y del depenir. Es la manifestación del borror de la mwerte y de la necesidad del terror como castigo" (1987:221-222).

As imagens que começaram a circular pela Nova Espanha também traziam visóes panorâmicas de cidades renascentistas e o desenvolvimento que alcançavam. Mas a decoração urbana e movimento nas ruas, tal como aparecem exemplarmente na ilustração de 1525 da Tragicomedia de Calixto y Melibea (figura 6), não surpreendeu os índios. O que lhes despertou a curiosidade, segundo os cronistas das Indias, foi principalmente a separação existente entre figuras e letras, algo estranho para eles, bem como os gestos das personagens baseados em relaçōes sociais às quais não estavam acostumados. Contudo, se compararmos este tipo de texto com os dos códices indígenas, encontraremos diferenças radicais: as relaçōes entre os sistemas visual e verbal são quase sempre intertextuais nos textos europeus, enquanto que nos indígenas, como já afirmamos, sistemas presentes no espaço do texto mantêm relaçóes intra- 
textuais. Os textos europeus daquele período expressam aparentemente uma isotopia de expansáo, enquanto que os mais representativos textos indígenas tendem para o oposto, isto é, para a contração. Talvez este fato possa ajudar a explicar a tendência de regressáo geralmente observada nas metáforas Nahuas, enquanto que a intertextualidade das imagens européias mencionadas manifesta uma inclinação contrária à regressão. Contudo, devemos nos conscientizar que oposiçōes dessa natureza não negam a possibilidade de textos tão díspares terem traços em comum.

A oposição indicada nos ajudará agora a caracterizar um tipo de metáfora que se desenvolveu em todos os estágios dos primeiros encontros de índios e europeus, e que deixou marcas significativas nas primeiras imagens que os povos de Nova Espanha criaram para expressar sua visão dos europeus. Por esta razáo, é relevante lembrar que o primeiro presente de Montezuma a Cortés foi em essência a materialidade de uma metáfora. Como nos relatam Harbottle \& Weigand: "Turquoise in this pre-Colombian Mesoamerican society clearly was more than an extrapagan-

Fig. 6: Tragédia de Calixto e Melibeia

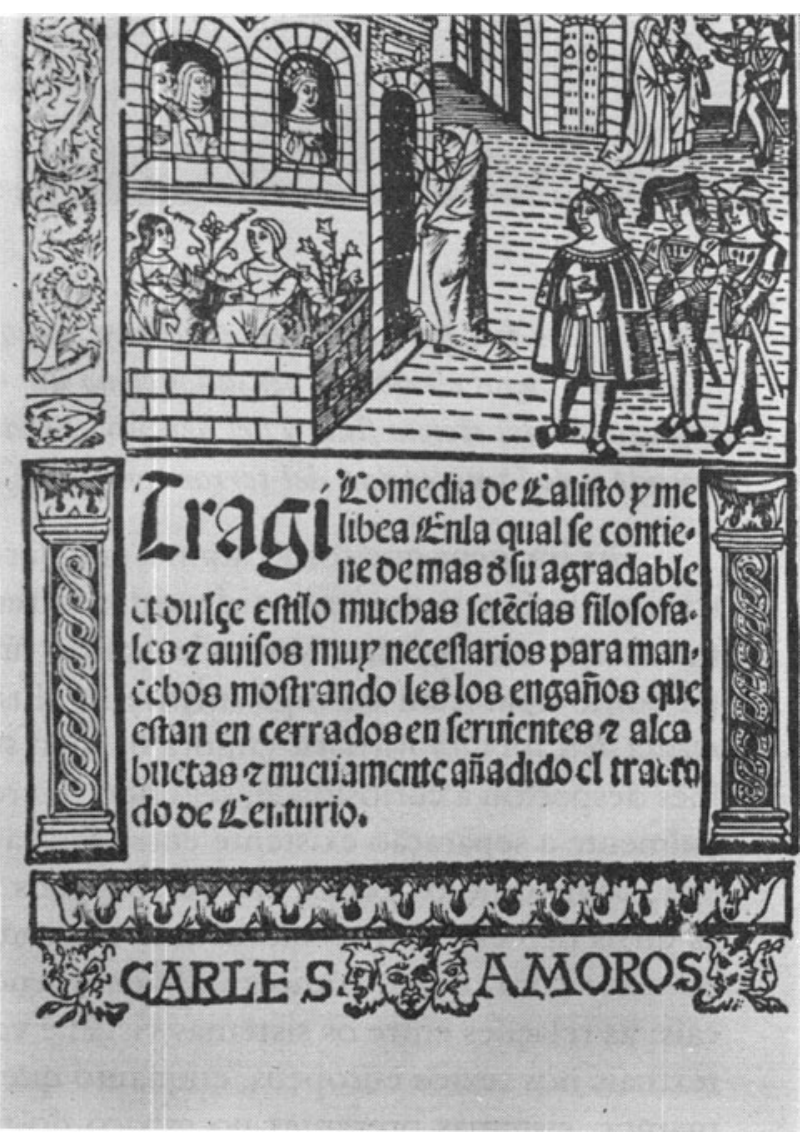

ESTUdOS AVANÇADOS 8(21), 1994 
thy paluable possession. The gem was also a metaphor for life in social and religious realms. Words of wisdom were likened to precious turquoise, and the stone became a symbol of noble status " (1992:7). Cortés reconheceu a importância simbólica da máscara, à sua maneira, mas obviamente não percebeu que pedras preciosas originárias de vários lugares distantes uns dos outros estavam juntas no objeto. Essa condensaçáo de pedras vindas de lugares diferentes e distantes, essa metáfora de uma contraçáo cujos significados profundos o Conquistador não foi capaz de advinhar, seriam descobertos somente quinhentos anos depois.

As metáforas que os índios criaram para nomear fenômenos fundamentais da natureza são de uma poesia comovente e instintiva. Os cronistas das Índias nos oferecem exemplos magistrais, mas nenhum se iguala ao de Sahagún. No capítulo XII do décimo primeiro livro de sua Historia general de las cosas de Nuepa Esparia, ele diz " En este primero parrafo se trata de la agua de la mar y de la mar, al cual llaman (sic) 'ttuatl', y no quiere decir 'dios del aguar ni 'diosa del aguar, sino quiere decir sagua marapillosa en profundidad y en grandeza. Lldmase tambion -ilbuicdati que quiere decir 'agua que se jureto con el cielor. Porque los antiguos babitadores desta tierra pensaban que el cielo se junta con el agua en la mar, como si fuese una casa que el agua son las paredes y el cielo esta sobre las. $\Upsilon$ por esto llaman a la mar illbuicdatl, como si dixesen 'agua que se junta con el cielo. Empero, agora después de perida la fe, y ya saben que el cielo no se junta con el agua ni con la tierra, y por eso llaman a la mar - butiatl, que quiere decir aggua grande y temeroso y fiera, llena de espumas y de olas, y de montes de agua, y agua amarga, salada o mala para beber, donde se crian muchos animales, que estdin en contino movimiento" (1988:800). A metáfora em pauta poderia ter como solução o termo borizonte, entendido como a linha na qual o céu e o mar dáo a impressáo de se juntarem. De qualquer forma, a metáfora indígena mencionada por Sahagún tem, além de suas ligaçóes com fenômenos naturais, um compromisso cerrado com os códigos culturais astecas.

Em seus comentários sobre as imagens do Códice Borbónico, referindo-se às personagens e composiçáo desta parte (figura 7) da página XVI, Paso y Troncoso diz o seguinte: " $E l$ cuadiro es del mayor interés, pues on el esta pintado el murdo entero, circusedado por las aguas que se juntan con el cielo, 'ilbuika-atl, aqui reprentadas por un marco de agrua que rodea todo el quadro y en cuya parte superior estin las estrellas del firmamento, dibujadas con sus dipersas magnitudes, brillantez y aspecto. Dentro del marco se pen, frente a frente, 'Tonatiubr o el sol, creador de las cosas naturales, y 'Xoloth, creador de las cosas monstruosas. Este ultimo viene pestido con arreos de 'Ketfalkdatl al pecho, la orejera corniforme, la diadema plegada en zig-zag, y hasta las puntas arredondadas del mastate de papel, 


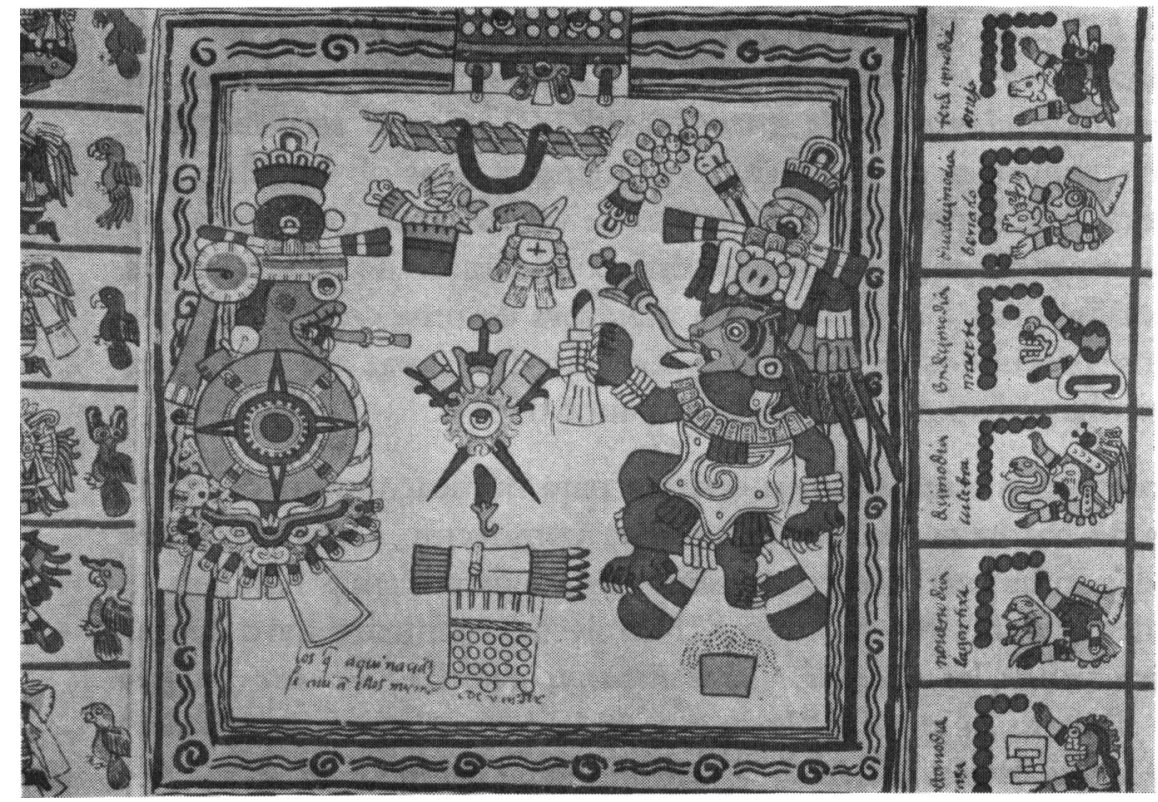

Fig. 7: Códice Borbónico

son adomos emblemdticos del dios del aire. No es menos interesante la zona del Sol bajo, significado proprio del pocablo 'Tlalxitonatiub', simbolismo doble para expresar que cuando baja el sol se acerca a la región de los muertos, y por su contacto con la tierra desprende papores que formarain las lluvias, de las cuales 'Tlálok' es numen" (1988:75). Nessa referência, a metáfora comentada por Sahagún está impregnada de significados relacionados com a corporalidade e, sem dúvida, com a intratextualidade intrincadamente manifesta nesta página do códice. A associaçáo do textual e corporal é inevitável na obra dos tlacuilos e tem, por exemplo, antecedentes majestosos na caligrafia chinesa, uma vez que, como nos diz Mandel, "Le calligraphe chinois traduit dans le caractire, par un investissement corporel et spirituel total, dे travers sa propre perception, la puissance de la pensée et du perbe, le sens dramatique du texte, FORME ET FOND ainsi confondus dans une parfaite osmose depiennent réalité pipante (1992:90)".

Tomadas genericamente, as metáforas da cultura Nauatl têm vínculos mítico-ritualísticos, cujos significados profundos se referem a configuraçôes sobre as quais algumas interpretações foram aceitas pelos mais sérios americanistas. Assim, ao estudar os ritos da mágica do amor Maia-yucateco, Flores menciona, entre outras, a coincidência cultural baseada no simbolismo numérico. Se no mito estudado o número nove simboliza os nove níveis do submundo aos quais as mulheres se direcionam a fim de "solicitar su participación en el ritual mágico y en la consecución del mismo (que el amante esquipo sea atraido irremisiblemente por la mujer )" (1991:11), na Espanha, conforme informaçăo fornecida por 
Aguirre Beltrán (1963), para uma mulher do século XVII pagar as dívidas ao marido ela tinha que desempenhar uma cerimônia mágica e de profecia durante nove semanas consecutivas. Esse tipo de coincidência, porém, indica outros aspectos de invariáveis culturais perseguidas pelos antropólogos, semioticistas e seguidores de teorias do inconsciente. Aqui não é o lugar para discutir tal paradigma. O que podemos dizer é que nele são engendradas imagens em que a Europa, apesar do seu enorme desejo de expansionismo, se olha com prazer e, nessa apreciaçáo, descobrimos os efeitos de uma viagem de regressão, no sentido freudiano, cujo destino final supóe uma chegada metafórica ao espaço do paraíso. Táo imaginária talvez quanto a que os companheiros de Colombo esperavam encontrar perto do equador. Quanto a isso, parece mais prudente, neste momento, considerar a tendência em direçáo à primoridialidade observada nos processos metafóricos de um lado e do outro do Atlântico. É o mesmo que dizer que os aspectos mais profundos da metáfora remetem ao primordial, àquele universo de contraçóes que se insinua quando nos defendemos das ameaças do mundo que nos cerca. Talvez seja por isso que irradiaçóes desse conflito, como uma convulsão subjacente, ganham intensidade toda vez que a História tenta enterrar sua presença. Mas, queiramos ou náo, a metáfora tem o poder inusitado de esmagar as desigualdades e sobreviver nas mais violentas hecatombes, semeando os territórios de qualquer cultura com imagens possuidoras de extraordinário alcance premonitório.

Esta imagem (figura 8) do Códice Durán tem, sem dúvida, a intençáo de traduzir a primeira visáo que os nativos da Nova Espanha

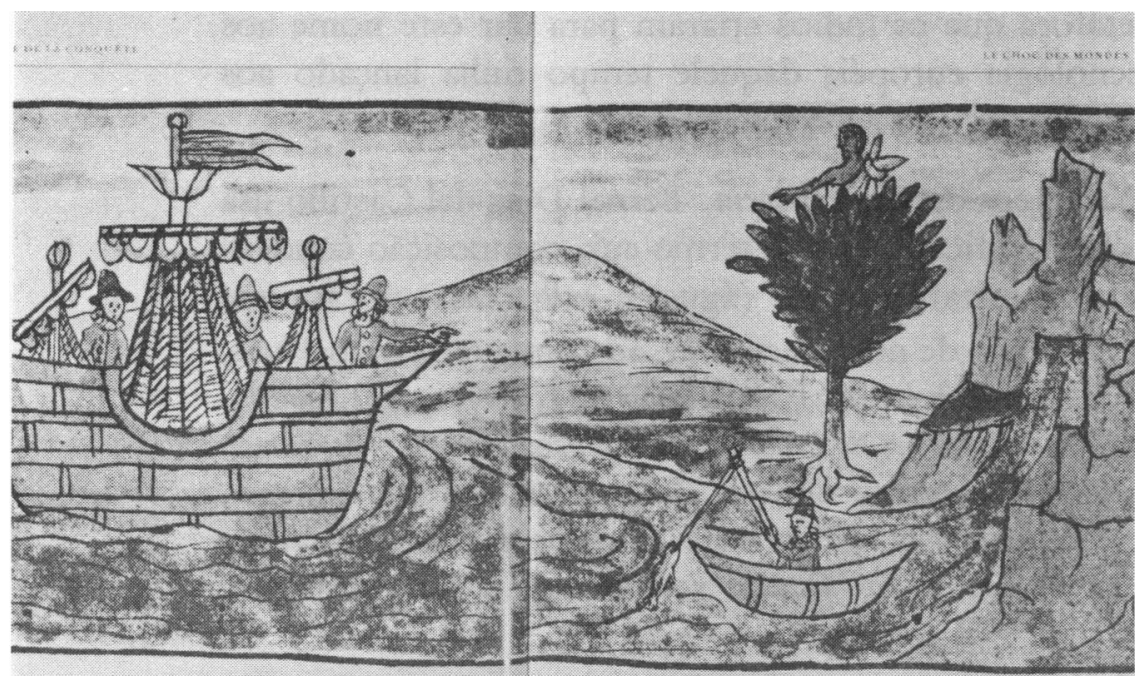

Fig. 8: Códice Durán 


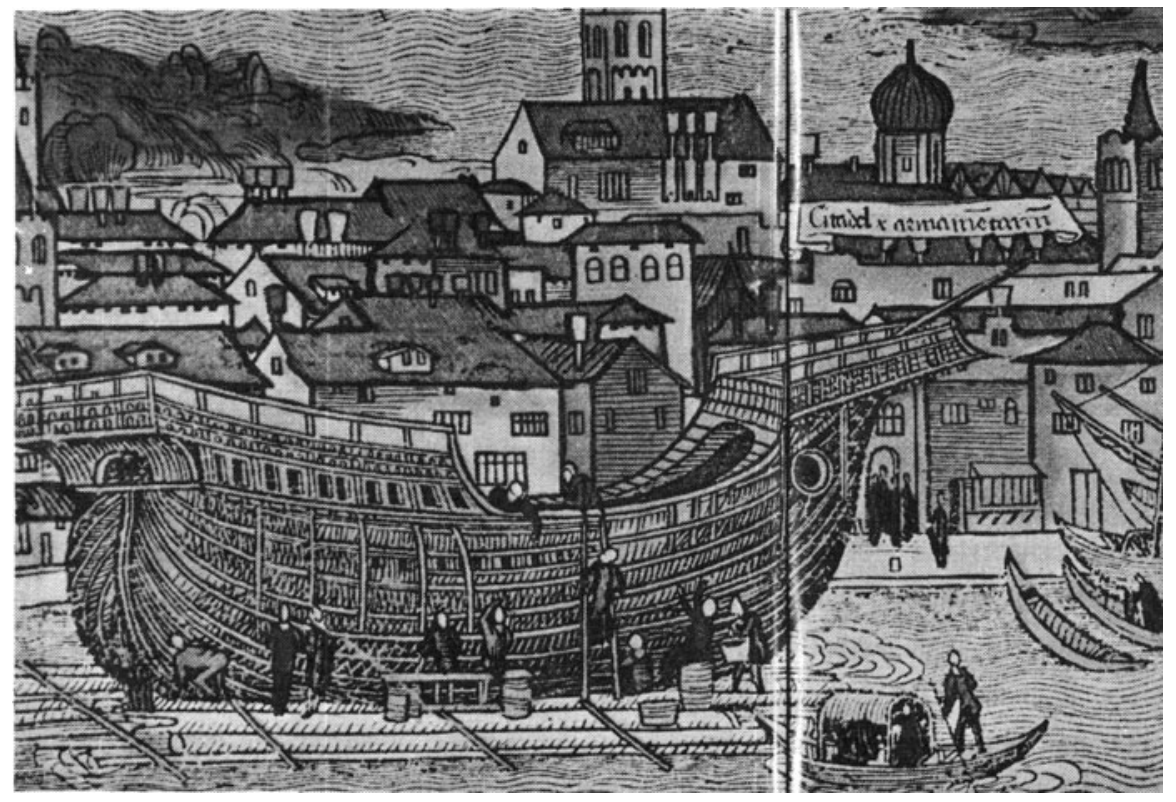

Fig. 9: Porto europen

poderiam ter tido dos europeus. Mas os cascos dos navios mais distantes estăo pintados como se fossem paredes de tijolos de uma casa. À primeira vista, temos a impressão de que estas imagens são inspiradas pelas gravuras européias, nas quais a casa e o navio aparecem juntos, como se quisessem falar um com o outro. Assim, nesta ilustraçáo (figura 9), a arquitetura urbana e a nau estão em perfeito diálogo, olhando um para o outro, como se quisessem perpetuar nos espelhos da História tudo sobre uma casa que está refletida num navio. As imagens do Códice Durán insinuam aspectos sutis desse diálogo sem, pelo que sabemos, tornar clara a metáfora que os índios criaram para dar este nome aos objetos que a tecnologia européia daquele tempo tinha lançado aos mares e haviam conquistado fama extraordinária.

Em várias passagens de sua Historia, Bernal Diaz del Castillo usa a palavra acale para significar nau, um termo cuja composição condensada revela sua origem metafórica: atl (água) e calli (casa) = casa que viaja sobre a água. É digno de nota que Alvar, ao comentar essa palavra, nos diz: "Molina, en su excepcional 'Vocabulario' $(11,1$ v), recoge 'acalli' como 'navio, barca, canoa' pero es de suponer que los bergantines castellanos que Cortts hizo construir tendrian distinta designación que las 'canoas', termino tatno que se desliza en la equivalencia. Baste pensar que Bernal usa canoa referida a las barcas de los aztecas y racal solo a las españolas " (1990:57).

O Códice Florentino também nos fornece imagens do encontro e, considerando os componentes da cena imaginada, a relação entre casa e 
navio é mantida, embora o motivo que permite essa associação seja de outra natureza. De qualquer forma, o que nos interessa é precisamente o peso metafórico que assume essa visão de um aspecto singular do que é europeu. É preciso reconhecer, todavia, que o importante.para o índio não é a singularidade, mas antes a impressáo causada pelo artefato que anda sobre os mares. Nesse sentido, pode-se trabalhar com a hipótese de que nesta imagem da Europa, pintada nos códices, o navio, em termos de objeto técnico e de sobrevivência, assume um valor mítico na configuração semântica, que os índios colocavam na sua designação. Este valor mítico, porém, encerra significados que só se tornariam evidentes mais tarde.

Embora freqüentemente orientados pelos cronistas, os índios continuaram pintando, entre outras coisas, casas e navios. Sem muita discussão com seus mestres, começaram a pintar casas com portas, algo que lhes era desconhecido, até que, um dia, muitas das portas apareceram qualquer semelhança com a realidade náo poderia ter sido coincidência - encerradas em imagens de pinceladas toscas. Apesar de a atraçáo que sentimos pelas conotaçóes reveladas por tal gesto ser grande, concentraremos nossa atençáo somente nas analogias dos navios pintados como casas, representados nos códices, pois o que nos concerne é observar que na metáfora do navio-casa encontramos os conjuntos da intratextualidade típicos da escrita asteca e que, em termos semióticos, o desvio retórico dessa figura talvez tenha um grau zero na primordialidade que a composição do Códice Borbónico, já citado, expressa tão bem plastica-

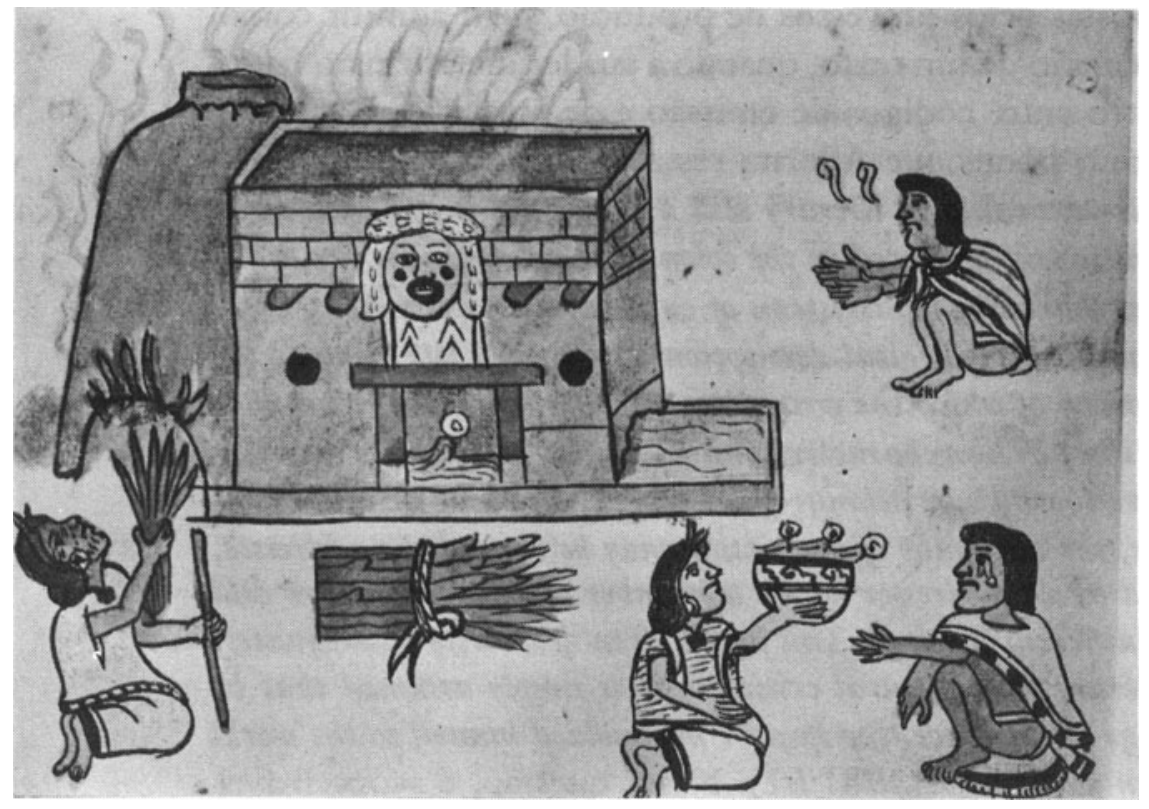

Fig. 10: Códice

Magliabechian 
mente. Queremos dizer com isso, por exemplo, que se o corpo das embarcaçóes vem à tona como uma construçáo feita de tijolos imitando a geometria representativa de habitaçōes (figura 10), a analogia que esta particularidade desencadeia transcende os aspectos meramente formais do icônico e está comprometida com os conceitos mais profundos da visão do mundo revelada nos textos dos códices.

De qualquer forma, a imagem, em termos de uma mensagem ou componente dela, não tem sentido só por causa das superdeterminaçóes de sua produção. Ela também tem a possibilidade de ampliar seu sentido, porque este é também parte do processo de recepção. Dessa perspectiva, as idéias de Eco sobre os códigos de emissáo e os códigos de recepção ainda não foram devidamente exploradas. A esse respeito, nosso trabalho assumiu a seguinte postura, desde o início: a mensagem tem sentido não só devido aos códigos de emissão, mas também por causa dos de recepção. A mensagem atinge seu significado mais amplo quando, a fim de a ler, usamos os significados dos dois conjuntos de códigos, uma vez que, só assim, poderemos nos certificar dos valores dos significados totalmente superdeterminados. Estamos tratando, em parte, de aproveitar os aspectos de noção de policulturalidade criada na escola de Tartu, desde que a crônica das Índias, como López-Baralt (1988:49-50) reconhece " se inserta dentro de la categoría de texto cultural descrita por Lotman y su grupo". No caso de alguns códices e também de tentativas de decifrá-los feitas por alguns cronistas, processos de policulturalidade sem dúvida se manifestam, uma vez que tanto em um caso quanto no outro, encontramos passagens nas quais a assimilação da outra cultura é evidente. Mas não seria prudente limitar fenômenos policulturais a determinaçóes impostas pelos processos de produçăo, nem admitir como errônea a compreensão de um texto, quando a sua leitura afirma o fruto de seu desencontro entre códigos de emissão e de recepção. Contudo, vale insistir sobre o ponto que Adorno ressalta quando nos diz: "The problem of the intertextuality in literary text and culture is complicated in the case of the artistic text produced in the colonial setting because one of the important features shared by most systems of cultural description is lacking. That is, the language of typological description is normally the same as the language of the society of which the writer is a member, with the result that the typology established by him characterizes not only the material be describes but also the culture to which be belongs (see Lotman, 1975:98). In the colonial text, however, the language of description may be that of the addressee, the colonizer, used by an addresser who is a member of another culture and the exponent of a different ideology. This fact is often dealt with inadequately in traditional literary and cultural criticism; it is simply assumed that by using the language of the other, the speaker bas molded himself to the world view of the foreign audience " (1981:51). Nessa questáo, é aconselhável 
manter-se no princípio de que "o factor temporal constituye otro criterio para la paloración del texto, ya que en el proceso de cambio cultural, este puede ganar o perder prestigio: un texto puede dejar de serlo, y un mensaje que no lo era, llegar a constituirlo. Es en este sentido que establecer la tipología del texto requiere un enfoque a la pez diacrónico y sincrónico. La segmentacion del texto cultural en signos es un problema más complejo, que impone atender tanto al texto como a la intención del autor y la interpretación del receptor (López-Baralt, 198:9) que coloca o problema exatamente como o faz Eco, "Il terzo punto che ci si era ripromessi di esaminare (cf. A.i,1V.3) era ise emittente e destinatario comunichino e recivono sempre in base allo stesso codicei. E lay risposta, data non solo da una teoria della comunicazione ma da tutta lá storia della cultura e délti esperienze di una sociologia della comunicazione, è: no" (1968:52).

À luz do exposto, é compreensível, de um lado, que Todorov nos diga que seu livro sobre a conquista da América " sera une tentatipe pour comprendre ce qui se passe ce jour-là, et pendant le siecle qui a suivi, à travers la lecture de quelques textes, dont les auteurs seront mes personnages. Ceux-ci monologueront, comne Colon: engageront les dialogues des actes, comme Cortés et Moctezume, ou celui des propos savants, d̀ la manière de Las Casas et de Sepulveda; ou celui encore, moins trident, de Duran et de Sabagrin avec leurs interlocuteurs indiens (1982:14). Contudo, por outro lado, embora o autor tenha montado um drama à maneira francesa clássica - referindo-se a uma unidade de tempo (os cem anos de conquistas), a uma unidade de lugar (a regiáo do Caribe e do México), e a uma unidade de ação (a percepção espanhola dos índios) ele não deixa claro que o diálogo, ou mesmo o monólogo, é através do trabalho de superdeterminação dos códigos e, nesse caso, os protagonistas não são precisamente os nomes citados, mas de preferência os códigos por eles manipulados ou os códigos que assumem uma função manipulativa. Dessa perspectiva, a metáfora acal acrescenta valores referenciais aos seus valores conceptuais e, acima de tudo, faz o diálogo entre códigos, aos quais nos referimos, perceptível. Para nos convencermos disso, é suficiente lembrar que na iconografia do período ao qual se refere Todorov as caravelas representam, tecnologicamente, o mais eficaz veículo entre o Novo Mundo descoberto e a Europa. São, ainda, configuraçóes semioticamente significantes, cujas conotaçóes sem dúvida transcendem o significado contemporâneo dos acontecimentos. Finalmente, não é estranho que as embarcaçóes se sobressaiam nos desenhos e ocupem lugar de destaque e, como já foi observado, desafiem as proporçōes das terras descobertas e dos pequenos povoados indígenas. As primeiras imagens do Novo Mundo foram criadas baseadas nas caravelas e nas costas das quais, pouco a pouco, foram se aproximando cada vez mais. 
É preciso, além disso, considerar que essas imagens foram superdeterminadas por uma estratégia necessária. Em suas exploraçóes iniciais os conquistadores preferiram náo se distanciar muito da costa. Eles permaneciam nos seus navios para descansar, isto $\epsilon$, fizeram deles verdadeiros lares. A descriçăo que Cabeza de Vaca faz da morte do capitáo Juan de Ayola ilustra essa questão: " $A 12$ dias del mes de octobre llego al puerto que dicen de la Candelaria, que es tierra de los indios payaguaes, $y$ por este puerto entró con su gente el capitán Juan de Ayolas, y hizo su entrada con los españoles que llevaba, y en el mismo puerto, cuando polvio de la entrada que bizo, $y$ dejo alli que le esperase a Domingo de Irala con los bergantines que bablan traido, y esperando tardó alli más de quatro meses, y en este tiempo padesció muy grande hambre: y conoscido por los paguayas su gran flaqueza y falta de sus armas, se comenzaran a tratar con ellos familiarmente, y como amigos los dijeron que los querian llevar a sus casas para mantenerlos en ellas, $y$ atrapesándolos por unos pajonales, cada dos indios se abrazaron con un criastiano, y salieron otros muchos con garrotes y diéronles tantos palos en las cabezas, que de esta manera mataron al capitán Juan de Ayolas y a ochenta hombres..." (1987:259). Ele continua o relato contando que a culpa da morte dos espanhóis é daquele que havia ficado com os bergantins. Ou melhor, que o europeu propiciava ao índio todos os elementos contextuais para as metáforas referenciais do tipo acal. A Europa, metonimicamente representada pelas naus, oferecia-se à vista, sempre a uma distância cautelosa. No caso da Nova Espanha, essa distância, acrescida aos extraordinários eventos acontecidos antes da chegada de Cortés contribuiu decisivamente para que as imagens se impregnassem de sentidos em que superstiçóes e presságios se confundiam com acontecimentos reais. Como já foi mencionado, ter sido avistada uma colina que se deslocava de um lugar para outro na orla do grande mar era algo que, de certa forma, reiterava maravilhas como aquela em que, um dia, uma enorme pedra começou a falar e proclamou a desgraça de Montezuma e o colapso de seu império.

Para Todorov, Colombo tinha se preocupado não em mostrar a verdade, mas em tornar as coisas adequadas a uma verdade por ele préestabelecida. Os sinais de terra que viu nos mares eram, na realidade, não sinais de terra, mas antes o desejo que o fossem. Todorov diz também que o Grande Navegador não prestou atenção à linguagem do outro $e$ conclui afirmando que "ce qu' il 'entend', donc, est simplement un resumé des lipres de Marco Polo et de Pierre d'Ailly " (1982:37). Todorov náo se dá conta que no mar dos sinais ele se comporta como o Almirante. Ele náo presta atenção aos sistemas semióticos do outro $e$, assim, quando lida com alguns signos das culturas indígenas, fingindo traduzi-los, freqüentemente os adapta aos seus desejos. O que Todorov 'entend', afi- 
nal, é um resumo de algumas das mais conhecidas passagens dos cronistas. Assim, ele chega à seguinte conclusão: "Meme si les chroniqueurs, espagnoles ou indiens, se trompent, ou mentent, leurs oeupres restent éloquentes pour nous: le geste que constitue chacune d'elles nous répele l'idéologie de son auteur, y compris lorsque le récit des événements est faux" (1982:125). Ao pensar dessa maneira, o modelo inscrito nos textos indígenas é separado do leitor e ele cai na armadilha que as metalinguagens européias armam-lhe toda vez que tenta abordar a cultura ameríndia sem se despojar do absolutismo de alguém que se crê o possuidor do saber superior e intocável. Como observador concreto, Todorov perde a oportunidade de abordar a hipótese do autor, da qual fala Zunzunegui (1992:87) porque ele não faz qualquer tentativa para decodificar a intratextualidade característica dos textos indígenas que cita. No que concerne à cultura asteca, uma atitude semelhante pressupóe, em princípio, distanciar-se da isotopia de contração e, em decorrência, eliminar do exercício da leitura o fator de analogia superdeterminada pelos procedimentos metafóricos da escrita que se plasma nos códices.

Chega-se à linguagem do outro quando os códigos de emissão e de recepção se encontram e se cruzam, da mesma maneira como os termos criados pelas metáforas se encontram e se cruzam. O outro é alcançado no instante em que a metáfora deixa de ser mera figura retórica a fim de assumir vitalidade. Conseqüentemente, o encontro se realiza através de identidades às quais nem Todorov nem Colombo chegaram, mas que estáo insinuadas nas metáforas elaboradas pelos índios tendo em mira traduzir seu próprio assombro sem trair - traduttore traditore - a arbitrariedade significante daqueles que estavam chegando. Não se pode descartar a idéia de que a metáfora acal, presa aos códigos de emissão, como vimos, desenterra da poeira da História a conjunção que, por natureza, existe entre o navio e a casa nos códigos de recepção - para simplificar, digamos, na língua espanhola.

É preciso reconhecer que, a partir dos feitos de Colombo, o planeta Terra vem se tornando cada vez menor. Hoje a Terra sobre a qual caminhamos é pouco maior que uma laranja mecânica. Ela pode ser definida metaforicamente como uma casa com pretensóes de ser confortável - uma construçáo na qual estão preservados, queiramos ou não, alguns dos mistérios das velhas catedrais medievais. Torres, cumieiras, agulhas de torre, cúspides, câmaras mortuárias em cruz, galerias de coro, capelas, campanários e rosetas certamente desapareceram. Mas os cantos impostos pelos planos de piso latinos ou gregos em cruz foram preservados. Parece oportuno lembrar que as caravelas usadas pelos portugueses durante o século XV tinham dois mastros com velas latinas. Delas, dos cantos, nos chegaram formas culturais de intimidade e, sobretudo, 
uma vaga agitação na penumbra em que estão escondidas as linguagens através das quais tanto as coisas fantasmagóricas quanto as do inconsciente se manifestam. Aduelas de abóboda, calotas, cornijas, modilhóes, peitoris, barras, parapeitos, telhas, calhas, balaustradas e canaletas expóem sua identidade às condiçóes meteorológicas. Armários, lambris, vigas, painéis esculpidos, estuques, assoalhos de tacos de madeira, armários de canto e lareiras estão amontoados internamente. Nomes que se referem a objetos feitos com o intuito de criar um espaço para seres humanos no qual eles habitualmente vivem o simulacro de quem, dia após dia, presume enganar a morte.

Vista, pois, nesse conjunto de particularidades, a casa é um mundo que, como um espaço inventado, não só é feito dos objetos que o integram, mas também das palavras que dáo nome a cada objeto. Assim, a casa é algo superdeterminado por um conjunto de códigos amplamente milenário. Nesse sentido, uma janela, por exemplo, na sua condiçáo de signo, não tem simplesmente como referente apenas o que o dicionário designa quando diz que é uma abertura na parede a fím de permitir a passagem de ar e luz. Quanto ao termo no sistema espanhol, pentana pode integrar um paradigma semântico-expressivo, no qual entram viento, pentana, pentosa. No caso de outros sistemas lingüísticos, digamos, o francês, o signo fenttre, comumente considerado como traduçáo correta de ventana, náo integra o paradigma semântico-expressivo no qual entram lexemas como pent, pente, penteuse etc. Ventana e fenttre não têm, portanto, a mesma origem. Săo signos produzidos por processos de codificação diferentes. Uma coisa é pensar uma janela como um orifício aberto numa parede a fim de permitir a passagem do vento, e outra, muito diferente, é pensar nela como um orifício aberto numa parede a fim de permitir a pessoas que moram lá dentro ver fragmentos do exterior. Essas duas maneiras de encarar a abertura na parede significam, conseqüentemente, diversos modos de representar nossas experiências e coexistir com nossas circunstâncias. Por esse motivo, tomar sentidos superdeterminados pela confluência de dois processos de codificação distintos à experiência daquela parte da casa supōe, em princípio, construir uma imagem de janela que se distancia do lugar comum. Uma imagem de janela, digamos, semelhante às imagens metafóricas criadas nos códigos ameríndios para representar coisas feitas pelo homem e coisas do mundo de maneira que tanto a primeira quanto a última revelem uma relaçáo ancestral com a corporalidade humana. Em suma, $\epsilon$ preciso criar imagens que exponham aos quatro ventos seus compromissos com as formas fonéticas e que abandonem as formas arbitrárias que os signos tomaram nas suas excursóes pelas estradas construídas pelo imperialismo da arbitrariedade, como as figuras geométricas que 
delimitam as páginas dos mais autênticos códigos ameríndios insinuam de maneira incomum; para no fim criar imagens como aquelas manifestas em acal, quando descobrimos que o sistema plástico sobre o qual se assenta a metáfora é uma representação cósmica cuja finalidade parece ter sido a de lutar contra as forças sombrias que hoje chamamos de pulsão da morte.

Intrinsecamente, a visáo do que é europeu, moldando aquela figura, reflete o mesmo desejo de sobrevivência entrevisto nas embarcaçōes quando as vemos como vestígios de cavernas remotas, nas quais nossos ancestrais tiveram seus primeiros sonhos de expansão, ou de navegar os oceanos, como Colombo nos relata em seu Diário: " $\Upsilon$ ast napegué fasta el dia al Ouesudeste, y amaneciendo calmó el viento y llovio, y asi casi toda la nocbe. $Y$ estuve asi con un poco viento fasta que pasaba de medio día y entonces tornó a ventar muy amoroso, y llepaba todas mis pelas de la nao: maestra $y$ dos bonetas y trinquete y cebadera y mezana y vela de gavia, y el batel por popa" (1965:7).

Poderíamos continuar enumerando outras partes do navio. Poderíamos falar, por exemplo, do cesto de gávea, do mastaréu da gávea, dos ovéns e pequenos botes, e nos surpreendermos quando os dicionários dizem que ovéns são cordas que prendem o mastaréu ao mastro ou que a cevadeira é uma vela sobre a verga atravessando o gurupés. Ficaríamos surpresos porque descobriríamos que as definiçóes usam metáforas e que algumas palavras não evitam confusōes homonímicas. Mas, se pensarmos no vento brando ao qual se refere o Almirante, e associarmos o pensamento ao que nós já dissemos sobre o vento, subitamente nos convenceremos que a caravela na qual Colombo e a nossa fantasia velejam é, na realidade, um acal.

\section{Referências Bibliográficas}

ADORNO, Rolena. On pictorial language and typology of culture in a new word chronicle. In: Semiotica, v. 36, n. 1/2, p. 51ä106, 1981.

AGUIRRE BELTRAN, Gonzalo. El proceso de aculturacion en la estructura colonial, MExico, NI, 196-.

ALVAR, Manuel. Americannismos on la bistoria de Bermal Dhaz del Castillo. Madrid, Ediciones Cultura Hispánica, 1990.

CABEZA DE VACA, Alvar Núńez. Nauffagios y comentorios. Texto restaurado y anotoda por Justo Garcla Momales, Madrid, Aguilar, 1987.

CODEZ, Mendoza. The Mexican marnuscript known us the colletion of Mendozat. 3 v. Londres, Waterlaw and Sons, 1938. 
DIBBLE, Charles E. \& ANDERSON, J. O. Florentino Codex. 11 v. Santa Fe, The School of American Research, 1950-1970.

DURAN, Diego. Historia de las Indias y de las Islas de Tierra Firme. 2 v. México, Porrúa, 1967.

DORS FÜHRER, C. Quetzalcóatl y Coatlicue. In: Cuadernos Hispanoamericanos, 449, p. 728, 1987.

ECO, Umberto. La struttura asente, Milano, Bompiani, IV ed., 1968.

ESCALONA, E. Tlacuilo, México, UNAM, 1989.

FLORES, Juan Antonio Carlos. Un ritual de magia amorosa mayaäyucateca: el Kay NictGa. In: Cuadermos Hispanoamericanos, Los Complementarios, n. 7/8, 1991.

GALARZA, Joaquín. Lire l'image astèque. Communications, 29, 15ä33, 1979.

GRUZINSKI, Serge. L'Amtrique de la conqute peinte par les indies du Mtacigue, Paris, Flammareion, 1991.

HARBOTTLE, G. \& WEIGAND, Phil C. Turquoise in preäColumbian America. Scientiff American, 266, p. 78ä85, 1992.

LEÓN-PORTILLA, Miguel. Visión de los pencidos. Relaciones indigenas de la conquista, México, UNAM, 12 ed., 1989.

LÓPEZ-BARALT, Mercedes. Icono y conquista: Guamán poma de Ayala. Madrid, Hiperión, 1988.

MANDEL, Ladislas. La magie de l'écriture: du visible à l'invisible. Communications et Langages, 91, p. 75ä97, 1992.

MELEGARI, Vezio. Come navigava. In ParalliäColombo, anno I, n. 4, 78ä81, 1991.

PASO Y TRANCOSO, Francisco del. Discusión, bistoria y explicación del Codice Borbonico (edición facsimilar). México, Siglo XXI, 1988.

ROCHA, Idilio. Até os santos duvidavam. In: Humbolt, 63, p. 4ä8, 1992.

SAHAGƯN, Bernardino de. Historia general de las cosas de Nucva Esparia, Madrid, Alianza, 2 v., 1988.

SOUSTELLE, Jacques. La vida cotidiana de los Aztecas on la propera de la conquista. México, FCE, 7 reimpresión, 1984.

TEZOZOMOC, Fernando Alvarado. Crónica Mexicayott, México, UNAM, 1975.

TODOROV, Tzvetan. La conquete d'Amtrique. La question de l'autre. Paris, Seuil, 1982.

VIEIRA, Padre Antonio. História do futuro (I). In: Obras Escollsidas, prefácio de António Sérgio e Hernâni Cidade. Lisboa, Livraria Sá da Costa, 1953.

ZUNZUNBGUI, Santos. Pensar la Imagen.Madrid, Cátedra, 2. ed., 1992. 


\title{
Resumo
}

Os códices mesoamericanos têm o mérito adicional de nos fazer ver traços inesperados de imagens de Europa de maneira mais precisa quando ganham nova expressão em outras culturas. Com isso em mente, o objetivo de nossa apresentação é explorar determinadas formas que surgem quando o intérprete dos códices mesoamericanos pára para pensar sobre o tipo de relação que os diferentes sistemas semióticos - pictográfico, ideográfico e fonérico - mantêm no espaço plástico do texto. Dessa perspectiva poderemos valorizar o significado poético das metáforas nas quais os ameríndios expressam visōes peculiares das gentes e coisas européias.

\begin{abstract}
The Mesoamerican codices enable us to see, with a certain degree of precision, unexpected traits of images of Europe when shaped in other cultures. With this in mind, our paper aims to explore certain forms that show up when the interpreter of the afore mentioned codices focuses his interest in the type of relationship that the different semiotic systems pictographic, ideographic and phonetic - maintain in the plastic space of the texts. From this perspective, it is possible to enjoy the poetic meaning of the metaphors used by the Amerindians in order to exprees unusual visions of European people and things.
\end{abstract}

Eduardo Peñuela Cañizal é professor e diretor da Escola de Comunicaçóes e Artes da USP.

Tradução de Martha Steinberg. O original em inglês - $A$ view of Europe in amerindian plastic expressions - encontra-se à disposiçáo do leitor no IEA para eventual consulta. 